The 6th TECHNIUM International

Conference 

Session Coordinator: Assistant Professor Sheeja Nair

Session Moderator: Dr. Raamani Thannimalai

Universiti Utara Malaysia

\section{The 6th TECHNIUM International Conference}

New decade on Social Sciences, Sustainable Future and Technology Development

Weblink: https://techniumscience.com/index.php/conference/index

The 6th Technium International Conference

Live Session for researchers worldwide

Title \& Abstract only conference

Email and WhatsApp full support

The conference is multidisciplinary and designed for Europe, Africa \& Asia researchers

BENEFITS

Increase your research visibility

Create a virtual experience

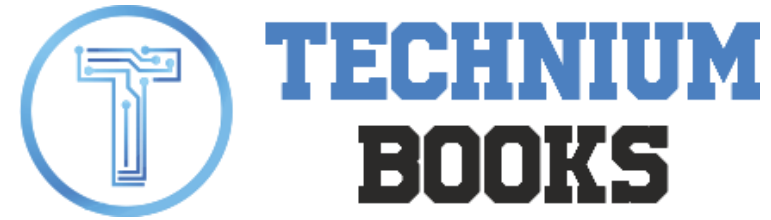


EDITORIAL OFFICE

TECHNIUM PRESS

E.U.

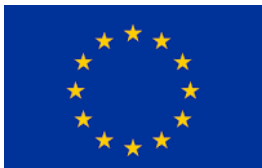

FIRST EDITION 2020

ISBN 978-606-95069-2-9 (PDF)

Cover image courtesy of Technium Science.

(C) 2020 by the author. The book is Open Access and distributed under the Creative Commons Attribution license (CC BY-NCND), which allows users to download, copy and build upon published work non-commercially, as long as the author and publisher are properly credited. If the material is transformed or built upon, the resulting work may not be distributed.

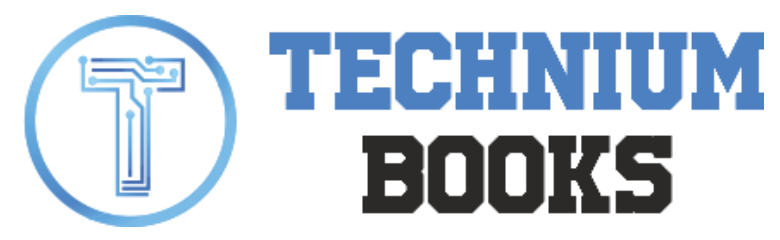


Dear TECHNIUM Friends,

It is with great delight we welcome you to the 6th TECHNIUM International Conference, general topic: New decade on Social Sciences, Sustainable Future and Technology

Development (6th TECHNIUM 2020) online on August 29-30, 2020.

Under the main theme "New decade on Social Sciences, Sustainable Future and Technology

Development" the conference will cover the diverse disciplines of Social Sciences and Applied Sciences from the present to the future. At 6th TECHNIUM 2020, academia and industry will gather to share valuable ideas and develop new collaborations. TECHNIUM 2020 will provide all participants a firm platform for a meaningful academic, industrial, social and cultural experience.

Conference date 29-30.08.2020

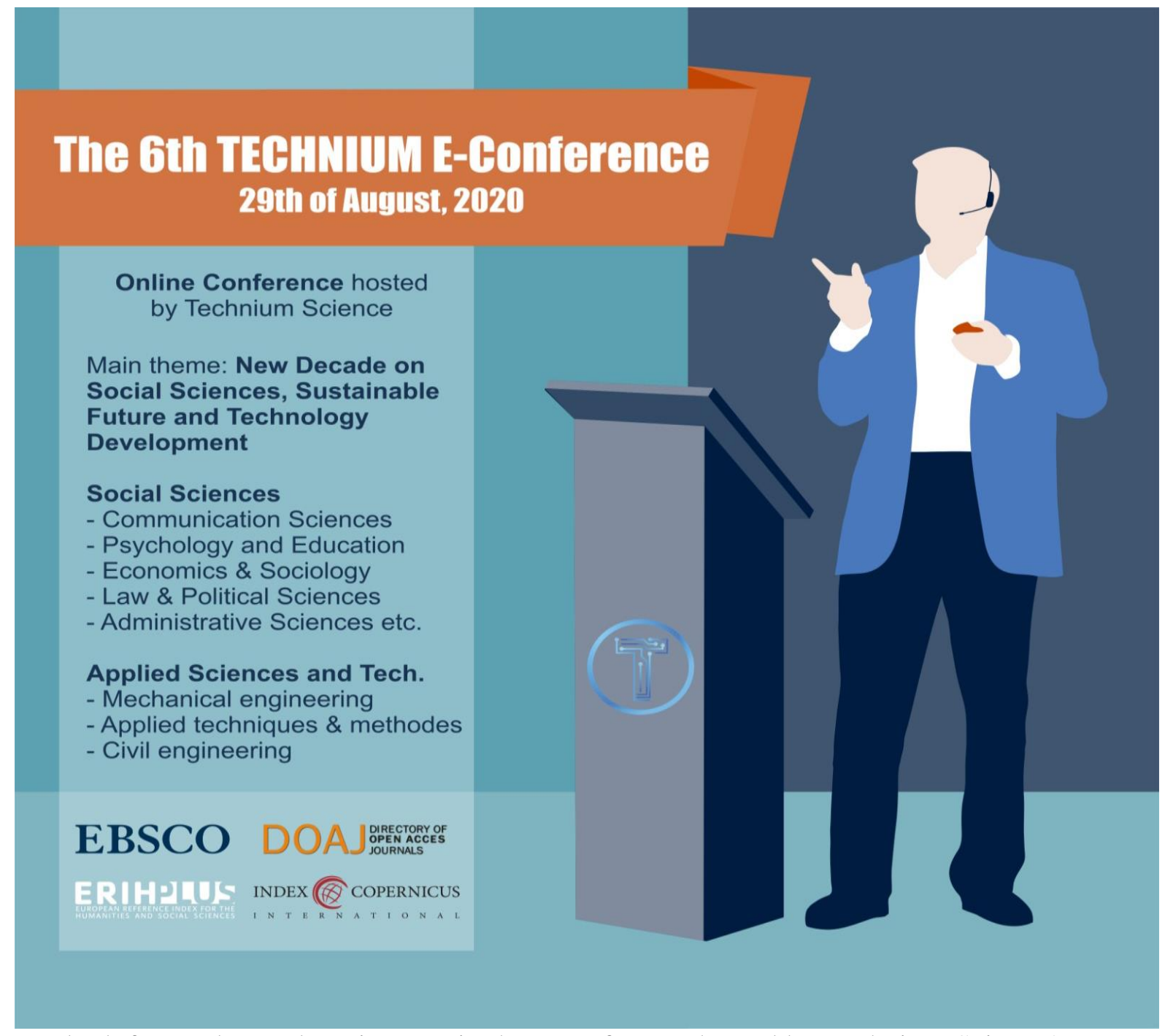

We look forward to welcoming you in the e-conference hosted by Technium Science! 
Conference session started on 29.08.2020 / 10.00 AM GMT and will used Webex Software.

The right date and time for conference start:

UK, Portugal, Cameroon 29.08.2020 / 11.00 AM

Spain 29.08.2020 / 12.00 AM

Germany, Egypt 29.08.2020 / 12.00 AM

Ukraine, Romania, Turkey 29.08.2020 / 1.00 PM

Iran 29.08.2020 / 02.30 PM

India 29.08.2020 / 03.30 PM

Japan 29.08.2020 / 07.00 PM

Sydney time 29.08.2020 / 08.00 PM

Session coordinated by Assistant Professor Sheeja Nair.

Moderated by Dr. Raamani Thannimalai

\section{The 6th Technium International Conference}

Live Session for researchers worldwide

Title \& Abstract only conference

Email and WhatsApp full support

The conference is multidisciplinary and designed for

Europe, Africa \& Asia researchers

\section{BENEFITS}

Increase your research visibility

Create a virtual experience 


\section{Welcome Message from the Conference Chair}

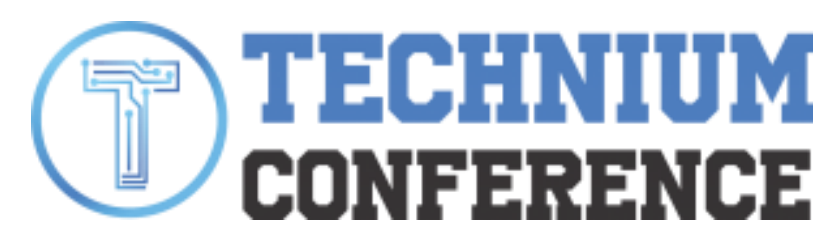

On behalf of the TECHNIUM 2020 organizing committee, I am honored and delighted to welcome you to The 6th TECHNIUM International Conference.

As a conference chair of TECHNIUM 2020, I know that the success of the conference depends ultimately on the many people who have worked with us in planning and organizing both the technical program and supporting social arrangements. In particular, we thank the Conference Coordinator and Moderators for their wise advice and brilliant suggestion on organizing the technical program; the Program Committee for their thorough and timely reviewing of the papers, and our sponsors who have helped us to keep down the costs of TECHNIUM 2020 for all participants. Recognition should go to the Organizing Committee members who have all worked extremely hard for the details of important aspects of the conference program.

The 6th Technium Conference was a perfect environment for research sharing and paper publishing. Hope to establish new connections related to my field of expertise and to support others. Increased conference visibility and higher impact of research will lead to worldwide recognition. Thank you all! 
This session promoted also the partnership with Instituto Internacional de Investigación y Desarrollo Tecnológico Educativo (INDTEC-Venezuela-Ecuador).

http://indteca.com/indtec/

INDTEC, C.A.

\section{Carina V. Ganuza}

Instituto Internacional de Investigación y Desarrollo Tecnológico Educativo (INDTEC-

Ecuador) and Universidad Nacional de Rosario (Argentina)

\section{Carina V. Ganuza:}

"We thank the representatives of Technium Science for the opportunity for growth and knowledge generated by this Sixth International Conference, which has promoted cultural exchange, experiences and alternatives from different parts of the world.

As a member of the Ecuadorian Institute for Educational Technological Research (INDTEC) and Development, we value and appreciate this first joint experience as a first step in building new and prosperous academic jobs.

We appreciate this vision of Technium in the propagation of academic research and we are committed to its dissemination, rescuing the solitary task of many academics and their moral role in the dissemination of the truth and in the study of the reality in which we are immersed." 


\section{Session Coordinator Assistant Professor Sheeja Nair}

Dwarkadas J Sanghvi College of Engineering, India

Career Scan

\begin{tabular}{||c||l||}
\hline \multicolumn{1}{|c||}{ Time Span } & \multicolumn{1}{c||}{ Organization } \\
\hline \hline July 2012 Onwards (Regular) & $\begin{array}{l}\text { D. J. Sanghvi COE Vile Parle (W) } \\
\text { Mumbai }\end{array}$ \\
\hline \hline & Sardar patel college of engineering \\
Jan 2012- June 2012 & Mumbai \\
\hline \hline \multirow{3}{*}{ June 2009- May 2011 } & TKR college of engineering \\
Hyderabad
\end{tabular}

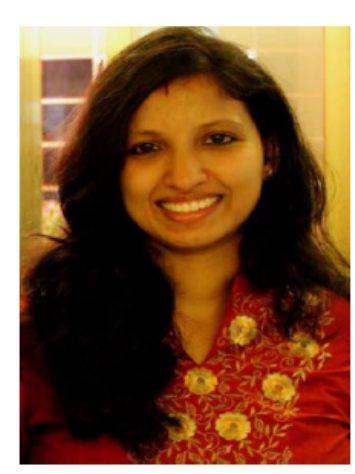

"Technium conference is a platform to connect with researchers, academicians, scholars across the globe who are working in diverse areas of research. Thanks for support and guidance!" 


\section{Session Moderator Dr. Raamani Thannimalai}

Universiti Utara Malaysia

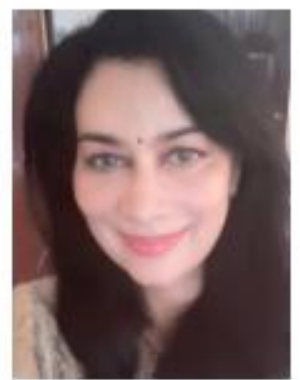

\section{Dr. Raamani Thannimalai:}

"Excellent, stimulating, challenging and thought provoking sessions. A worthwhile educational mind-opening experience.

Conference organizers were very systematic and considerate.

Thank you Technium for your excellent organization and an amazing and knowledge building. One of the best virtual conferences so far.

Really...you did a good job... so efficient and professional." 


\section{CONTENT}

\section{Opening Presentations}

Session Coordinator Assistant Professor Sheeja Nair

Session Moderator Dr. Raamani Thannimalai

Invited speaker - Jose Luis de Carvalho Azpiazu

Invited speaker - Prof. Madya Dr. Arumugam A/L Raman

\section{Sustainable Future and Technology Development}

Determination of Sensitivity and Adaptive Capacity for Prefabricated Housing Estates András Horkai, Gyula Kiss

Creation and Fields of Application of Digital City Models

András Horkai, Péter Fejes

Utilization and efficient waste management system

Sheeja Nair, Dr. Avinash More

The influence of the coastal relief on the navigation and seaborne trade in the Black Sea Romeo Bosneagu, Ionut Cristian Scurtu

Extended reality technologies for sustainable development and administration of cultural spaces

Alex Butean, Anca Morar, Andrei Daian, Alin Moldoveanu

Robot behavior and distance estimation in indoorgml maps using combinatorial and sampling-based planning approaches

The role of advertising in promote social marketing in case of private education in Ethiopia Derese Simegnew

Modes of hydraulic failure in soil mechanics

Farhad Sakhaee 


\section{New decade on Social Sciences}

Tension in the context of the COVID 19 crisis: Ecuadorian Political System and Exacerbation of the Austerity Plan (March-May 2020)

Instituto Internacional de Investigación y Desarrollo Tecnológico Educativo (INDTEC-

Ecuador) and Universidad Nacional de Rosario (Argentina)

Carina V. Ganuza

Academic profession and digital communication

Sandro Serpa

COVID-19. New and old social inequalities

Sandro Serpa

Impact of COVID-19 on Higher Education Teaching Delivery: Faculty perceptions

Deepanjana Varshney

Sociology and digital inequalities

Sandro Serpa

Sociology, society and open access

Sandro Serpa

Transformational And Transactional Leadership: Effects On Teacher Commitment In Malaysian Primary Schools

Arumugam Raman, Raamani Thannimalai

Content link: https://techniumscience.com/index.php/conference/issue/view/6th-conference 


\section{Peer Review Statement}

All papers published in this volume of $\boldsymbol{6}^{\text {th }}$ Technium 2020 been peer reviewed through processes administered by the proceedings Editorial. Reviews were conducted by expert referees to the professional and scientific standards expected and published in partner journals. 


\section{Welcome to Technium Science}

Technium Science is an international center for supporting distinguished researchers, teachers, scholars and students who are researching various areas of Science and Technology. Technium Science wishes to provide good chances for academic and industry professionals to discuss recent progress in various areas of Science and Technology. Technium Science organizes many international conferences, symposia and workshops every year, and provides sponsor or technical support to researchers who wish to organize their own conferences and workshops. Technium Science also publishes high quality academic international journals and books. Technium Science journals are indexed in DOAJ, ROAD, RePEc, DRJI, EZ3, Ulrich's and Index Copernicus.

Participation is confirmed by participation certificate issued to all online presenting authors. The objectives of the International Scientific Conference - Technium 2020 are to bring together research and education and to provide a networking opportunity for academics, professionals active in these domains. International publishing and recognition of scientific work.

Technium Conference 2020 brings together researchers and practitioners (young and experienced) interested in strengthening the scientific foundations in the fields of Engineering, Sciences, Information Technology, Ecology \& Marine research, Technical research.

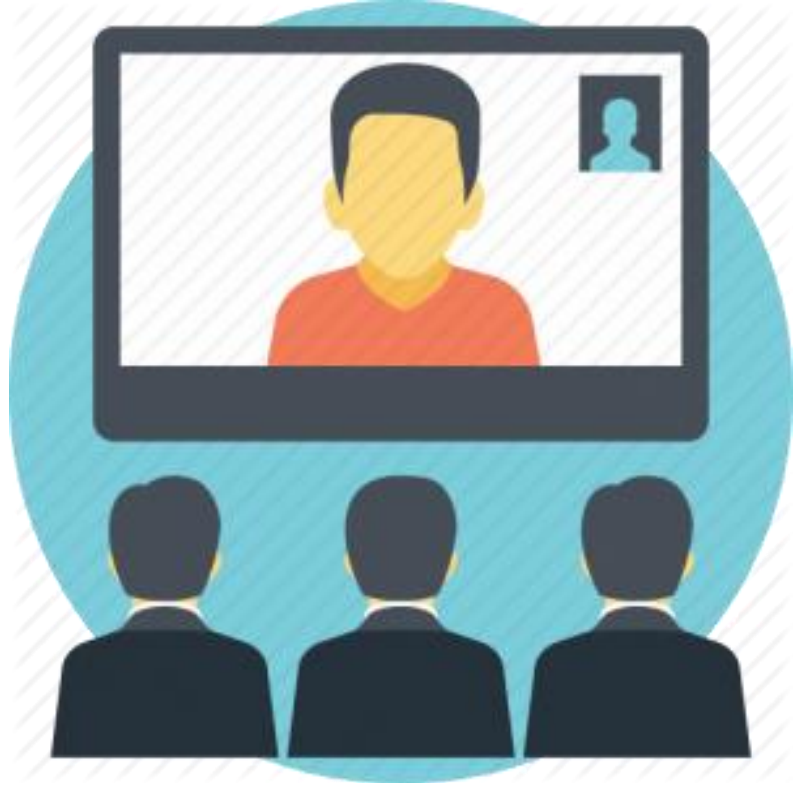

Selected papers will be published in:

Technium: Romanian Journal of Applied Sciences and Technology (ISSN: 2668-778X)

Technium Social Sciences Journal (ISSN: 2668-7798) 


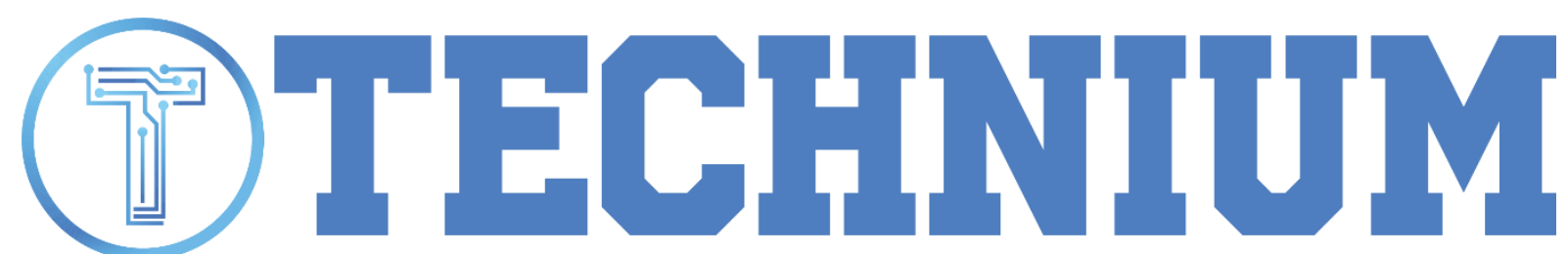

\section{Technium: Romanian Journal of Applied Sciences and Technology (ISSN: 2668-778X)}

https://techniumscience.com/index.php/technium

and

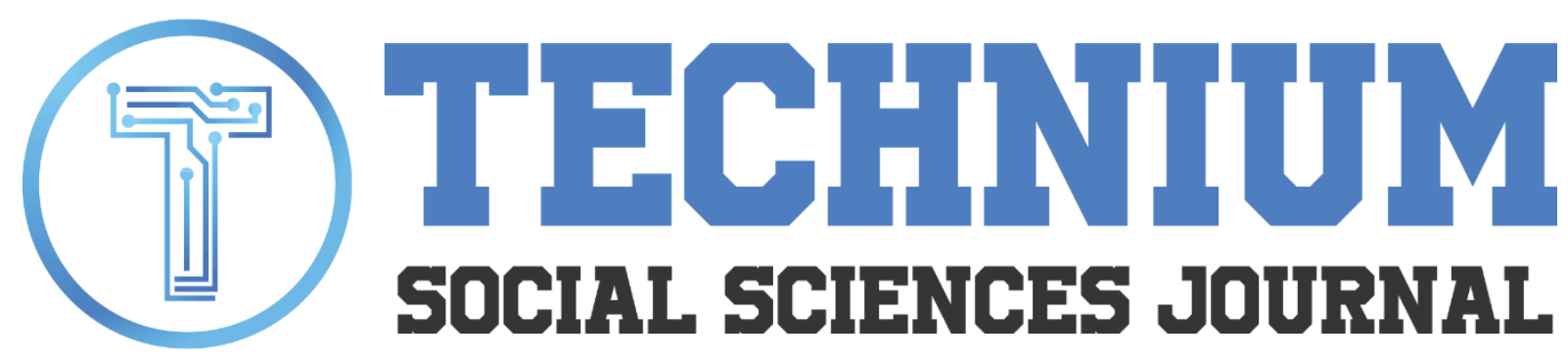

Technium Social Sciences Journal (ISSN: 2668-7798)

https://techniumscience.com/index.php/socialsciences

\section{THE ROLE OF THE SCIENTIFIC COMMITTEE}

Join Scientific Committee - send your request and your CV to office@techniumscience.com

- Lead the development and oversee the implementation of the Scientific Programme

- Members of the Scientific Committee represent major scientific disciplines for research objectives.

- Provides a forum for sharing knowledge and experience.

- Scientific Committee members act as Stewards to ensure continued quality and scientific integrity of Manuscripts and Reports.

- Network with key stakeholders to share and promote Technium output that contributes to informed, reliable and science-based chemicals management decisions.

- Highlight the need to update Technical Reports in the light of new knowledge. 
Join Scientific Committee - send your request and your CV to office@ techniumscience.com

The Scientific Committee is responsible for designing and proposing the annual research agenda and work programme as well as for overseeing the implementation of the approved activities. Moreover it formulates the longer-term research strategy of the network.

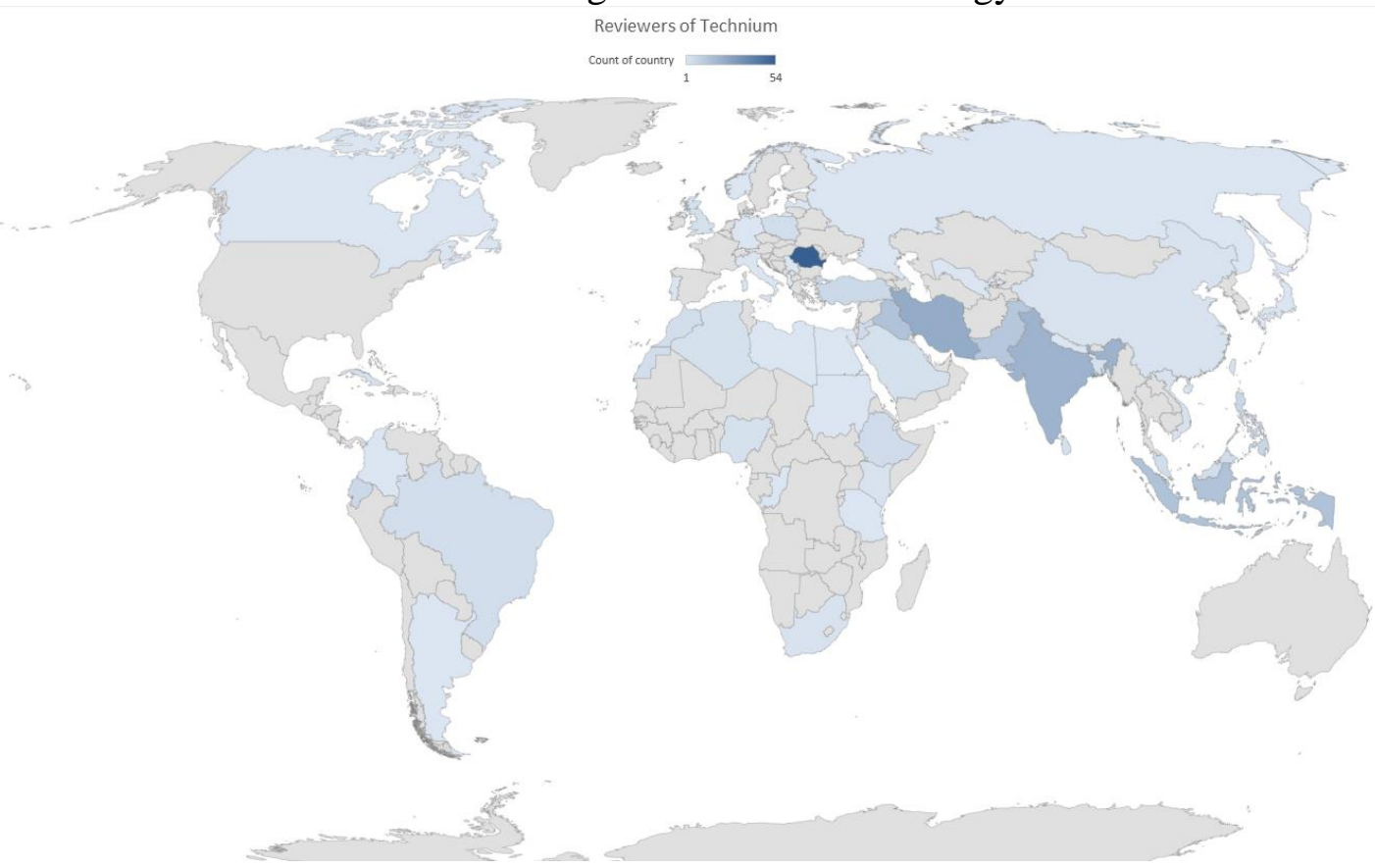

Specifically, the role of the Scientific Committee is to:

- Conceptualise and design the workshop programmes and oversee the selection of papers and participants;

- Advise on, and contribute to, the scientific content of the Network's website;

\section{Author responsibility}

The authors are exclusively responsible for the contents of their submissions, the validity of the experimental results and must make sure that they have permission from all involved parties to make the data public.

It is the responsibility of each author to ensure that papers submitted are written with ethical standards in mind, concerning plagiarism. Please note that all submissions are thoroughly checked for plagiarism. If an attempt at plagiarism is found in a published paper, the authors will be asked to issue a written apology to the authors of the original material. Any paper which shows obvious signs of plagiarism will be automatically rejected and its authors will be banned for a duration of three years from publishing with us. The authors will receive proper notification if such a situation arises. Information on what constitutes plagiarism is provided below. 


\section{Plagiarism: Definition and Context}

Plagiarism, where someone assumes another's ideas, words, or other creative expression as one's own, is a clear violation of scientific ethics.

\section{Plagiarism may constitute the following:}

Word for word, or almost word for word copying, or purposely paraphrasing portions of another author's work without clearly indicating the source or marking the copied fragment (for example, using quotation marks);

Copying equations, figures or tables from someone else's paper without properly citing the source and/or without permission from the original author or the copyright holder.

Self-plagiarism, as a related issue, is the word for word or almost word for word reproduction of portions of one's own copyrighted work without proper citation of the original material.

Any text, idea, paraphrase from any public source (Internet, published papers, printed or eBooks etc.) which is already available to the readers must be cited, irrespective of the authors. It is not allowed to repeat the same arguments and ideas, even when they have first been published in little known publications with limited circulation in other fields. The exception to this is if the paper features a "Related Work" section. It is unacceptable that research results from other papers be presented as though they were original work from the present paper.

Any text that needs to be reproduced "as is" should be quoted, and proper references provided. Before sending their contributions, the authors should read and document themselves about plagiarism and self-plagiarism. There is no excuse for lack of knowledge on this matter.

\section{OFFER FOR SPONSORS for Technium Science conferences}

\begin{tabular}{|l|c|c|c|}
\hline Benefits & $\begin{array}{c}\text { GOLDEN } \\
\text { SPONSOR } \\
\text { (Min. 3.000 } \\
\text { Euro) }\end{array}$ & $\begin{array}{c}\text { SILVER } \\
\text { SPONSOR } \\
\text { (Min. } \\
2.000 \\
\text { Euro) }\end{array}$ & $\begin{array}{c}\text { BRONZE } \\
\text { SPONSOR } \\
\text { (Min. } \\
1.000 \\
\text { Euro) }\end{array}$ \\
\hline $\begin{array}{l}\text { Sponsor's name and logo on the } \\
\text { conference website, with quick } \\
\text { link to the sponsor's webpage }\end{array}$ & Yes & Yes & Yes \\
\hline $\begin{array}{l}\text { Sponsor's name and logo } \\
\text { included in the conference's } \\
\text { session opening }\end{array}$ & Yes & Yes & No \\
\hline $\begin{array}{l}\text { Sponsor's name and logo } \\
\text { included in the conference's } \\
\text { documents Yes }\end{array}$ & No & No \\
\hline \multicolumn{2}{|c|}{ CNTACT } \\
\hline
\end{tabular}

